\title{
Osteoporosis of Crohn's disease: A critical review
}

\author{
NEENA S ABRAHAm MD, RichaRd N FEDORAK MD
}

\begin{abstract}
NS ABRAHAM, RN FEDORAK. Osteoporosis of Crohn's disease: A critical review. Can J Gastroenterol 1996;10(5):317-321. Osteoporosis has long been a recognized complication of Crohn's disease (CD), with a documented incidence ranging from 31\% to $65 \%$. The cause of osteoporosis in Crohn's patients is likely multifactorial; corticosteroids, inflammatory cytokines, small bowel resection and the resultant calcium and vitamin D deficiencies, hypogonadism, malnutrition and the cachexia of inflammation all play a role. However, the mechanism responsible for osteoporosis associated with CD remains unclear. Treatment of decreased bone density in CD patients has been limited to calcium and vitamin D replacement. The present understanding of the pathophysiology, mechanism and treatment of osteoporosis in CD is reviewed, with the focus on the role of steroid-induced osteoporosis and the use of bisphosphonates.
\end{abstract}

Key Words: Bisphosphonate, Crohn's disease, Inflammatory bowel disease, Osteoporosis

\section{Ostéoporose et maladie de Crohn : résumé de synthèse}

RÉSUMÉ : L'ostéoporose est depuis longtemps reconnue comme une complication de la maladie de Crohn, avec une incidence documentée allant de $31 \%$ à $65 \%$. La cause de l'ostéoporose chez les patients atteints de maladie de Crohn est probablement plurifactorielle : corticostéroïdes, cytokines inflammatoires, infection de l'intestin grêle et déficit secondaire en calcium et vitamine D, hypogonadisme, malnutrition et cachexie de l'inflammation ont tous un rôle à jouer. Toutefois, le mécanisme responsable de l'ostéoporose associé à la maladie de Crohn reste mal élucidé. Le traitement de la perte de densité osseuse chez les patients atteints de maladie de Crohn s'est limité à l'administration de calcium et de vitamine D. Cet article passe en revue l'état actuel de nos connaissances sur la physiopathologie, le mécanisme et le traitement de l'ostéoporose dans la maladie de Crohn et s'attarde au rôle des corticostéroïdes dans l'ostéoporose et à l'emploi des biphosphonates.
$\mathrm{T}$ he association between Crohn's disease (CD) and metabolic bone disease has long been recognized. Early studies documented an incidence of osteopenia or clinical osteoporosis ranging from $31 \%$ (1) to $65 \%$ (2). The clinical significance of osteoporosis lies in its morbidity and mortality, which are solely attributable to fractures. In CD the fracture rate has been documented at 6\% (3). These impressive rates are likely to be underestimates. Most early studies relied on a variety of radiologic methods to detect osteoporosis before the clinical onset of fragility fractures. These insensitive methods, which included radiographical skeletal survey and quantitative computed tomography (CT), lacked the precision of dual energy $\mathrm{x}$-ray absorptiometry, which is now widely available. This technique is not only more precise than conventional methods in assessing bone mass in both axial and appendicular views, but also uses a low radiation dose and is clinically acceptable to both physicians and patients.

\section{CLINICAL SIGNIFICANCE}

Bone mass is the major determinant of fracture risk. It has been suggested that, for every reduction in bone density of $1 \mathrm{SD}$, fracture risk increases by 1.5 to 3.0. The strength of this predictive relationship is similar to that of hypertension and stroke, or hyperlipidemia and coronary artery disease (4).

Clinically, there are accepted densitometric criteria for the assessment of bone mass. These criteria have been developed for women, primarily through a multitude of prospec-

Division of Gastroenterology, University of Alberta, Edmonton, Alberta

Correspondence: Dr RN Fedorak, University of Alberta, 522 Newton Building, Edmonton, Alberta T6G 2C2. Telephone 403-492-6941, fax 403-492-3744, e-mail richard.fedorak@ualberta.ca

Received for publication October 23, 1995. Accepted April 10, 1996 
tive and cross-sectional studies involving hormone replacement therapy for postmenopausal women. These thresholds are based on T scores, SD scores expressed in relation to reference mean values obtained in healthy young adults with normal bone densities. Normal bone density is described as $T$ value greater than 1 . T values between -1 and -2.5 suggest osteopenia, while osteoporosis, a further clinical deterioration in bone mineral density (BMD), correlates significantly with $T$ values less than -2.5 . Criteria for men have not been established (4).

\section{PATHOPHYSIOLOGY}

Histologically, osteoporosis is characterized by bone loss and disruption of bone micro-architecture. Osteoporotic bone has a decreased bone volume and displays a lowered mineralized matrix per unit volume. As well, it features decreased trabecular bridging, providing fewer struts for support than healthy bone. Although osteoporosis can affect all bone, trabecular bone (vertebrae, femoral head and distal radius) tends to be much more affected by osteoporosis than compact or cortical bone (shaft of long bones). The reduced mass of trabecular bones provides an increased risk of collapse or fracture, as can be seen in the predominance of compression fractures of the vertebrae and fragility fractures of the femoral head and distal radius.

Bone is a living organ that is constantly undergoing renewal through remodelling. Control of bone remodelling is complex and only poorly understood. It is based on a cycle of resorption followed by formation. This cycle is referred to as coupling.

At the cellular level, the most important mechanism involved in osteoporotic bone loss is that of increased bone turnover, during which the number of remodelling units is increased, resulting in an increase in the percentage of bone surface occupied by resorptive cavities. Secondarily, a negative remodelling imbalance exists, in which the amount of bone formed within a remodelling unit is less than that resorbed. This combination leads to bone loss (4).

The rate of bone formation or bone resorption can be assessed by biochemical markers. Markers of bone resorption include urinary excretion of hydroxyproline, $\mathrm{N}$-telopeptide, serum tartrate-resistant acid phosphatase, pyridinoline and deoxypyridinoline. Bone formation rates can be biochemically assessed using serum alkaline phosphatase, osteocalcin and procollagen peptides.

\section{MECHANISM OF OSTEOPOROSIS IN CD}

The cause of osteoporosis experienced by Crohn's patients is likely multifactorial, with corticosteroids (5), inflammatory cytokines (2), small bowel resection and the resultant calcium and vitamin D deficiency (6), hypogonadism (4), malnutrition (1) and the cachexia of inflammation all playing roles in the disease process. The mechanism responsible for osteopenia and osteoporosis in $\mathrm{CD}$ is unclear. Many investigators have supported theories involving increased bone turnover or negative remodelling imbalance. Hessov et al (7), for instance, found normal bone turnover but speculated that the reduction in bone mass was due to a negative remodelling imbalance. In comparison, Croucher and associates (8) found a significant reduction in bone turnover and evidence of a negative remodelling balance, due mainly to a reduction in the amount of bone formed within each remodelling unit.

Inflammatory response: Other possible causes of osteoporosis in CD patients involve abnormalities of the mononuclear phagocytic system, causing excessive resorption by osteoclasts or mediators from the inflamed gut and triggering osteoclast activity. Cytokines, which are released from the inflamed gut and regulate osteoclast function, include interleukin-1, tumour necrosis factor, transforming growth factor-alpha, interferon-gamma, interleukin-1 receptor antagonist and interleukin-4 (9). Bjarnason et al (2) suggested that a selective increase in osteoclast markers implies an increased bone breakdown without compensatory increase in bone formation, which may reflect lymphokine-induced activation of osteoclasts.

Controlling the inflammatory response in CD may contribute to improvements in bone metabolism. In patients with quiescent $\mathrm{CD}, \mathrm{BMD}$ is decreased in only $30 \%$, with no sign of increased bone resorption or decreased formation biochemically detectable (10). Abitol's group (3) found a change in BMD that equalled $-6.2 \pm 7 \% / y e a r$ in cases of active disease and $+0.9 \pm 4 \% /$ year $(P<0.002)$ in cases of inactive disease. As well, patients with active IBD experienced rapid and significant $(-6 \%)$ cortical and trabecular bone loss which stopped with suppression of the inflammatory process through use of immunosuppressives, ileoanal anastomosis or low dose corticosteroids. Those researchers concluded that early control of disease activity may prevent osteopenia and the associated late spontaneous fracture.

Corticosteroids: The role corticosteroids play in developing the osteoporosis of $\mathrm{CD}$ remains a mystery. It is known that steroids affect both bone resorption and formation. Corticosteroids exert a direct effect on the proliferation and differentiation of osteoblast precursors and the function of mature osteoblasts, which contain receptors for glucocorticoids. Glucocorticoid use also reduces local production of prostaglandin $E_{2}$ and insulin-like growth factor-1, while simultaneously increasing skeletal sensitivity to the effects of parathyroid hormone and 1,25-dihydroxyvitamin $\mathrm{D}$. These effects are likely exacerbated in men by a reduction in circulating testosterone levels and in woman by a reduction in the production of gonadal hormones. These effects appear to result from inhibition of gonadotrophin and adrenocorticotropic hormone secretion by the pituitary gland and from direct effects on the gonads (4).

Steroid effects on bone resorption involve a complicated interaction among increased parathyroid hormone secretion secondary to calcium malabsorption; increased renal calciuria secondary to inhibition of its reabsorption in the renal tubule; and sex hormone deficiency. Calcium malabsorption from the gut is inhibited by a mechanism that is independent of vitamin D. Direct stimulation of osteoclast function by 
glucocorticoids may occur but this has not been consistently demonstrated (11).

Corticosteroid-induced rapid bone loss: The major effect of long term corticosteroid use is inhibition of osteoblast proliferation and function. Histomorphometric studies of patients with corticosteroid-induced osteoporosis have generally shown low or normal bone turnover accompanied by a negative remodelling imbalance due to reduced bone formation (12). Evidence suggests that, in the early stages of steroid therapy a rapid loss of bone, especially cancellous bone, occurs; this process is not completely understood. Lo Cascio et al (13) and Reid and Heap (14) suggested that increased bone resorption occurs at that time. This rapid period of bone loss that follows the initiation of corticosteroid therapy is followed by a slower, but continuing decline in BMD (14).

Other investigators disagree with the idea of initial rapid bone loss. In a two-year longitudinal study Ghosh et al (9) found no correlation between rate of bone loss and prednisolone therapy. BMD and biochemical parameters were measured in $15 \mathrm{CD}$ patients and $15 \mathrm{UC}$ patients, all of whom were newly diagnosed. Densitometry was performed initially and after one year. Eleven of the $15 \mathrm{CD}$ patients scored more than 150 on the Crohn's Disease Activity Index, indicating active disease. Ten of the 15 UC patients had Truelove indexes suggestive of active disease. Repeat measurements were taken in 23 patients, 20 of whom received steroids, to assess progressive bone loss and the effects of therapy. Mean cumulative corticosteroid dose between initial and followup BMD measurements was $2.82 \mathrm{~g}$ (SD $3.75 \mathrm{~g}$ ). Mean spine $\mathrm{BMD}$ was $0.88 \pm 0.17$ in patients with $\mathrm{CD}$. One year later, the repeat measurement spine score was 1.37 (SD 0.82), a finding not significantly different from initial measurements. Those investigators concluded that their study failed to confirm the theory that rapid bone loss occurs following initiation of prednisone therapy.

Effects of cumulative corticosteroid dose: Although there is conflicting evidence arising from cross-sectional studies, most investigators believe that cumulative corticosteroid dose and its effect on ostoid formation are crucial to corticosteroid-induced osteoporosis. Motley and co-workers (15) found a significant correlation between the amount of corticosteroid prescribed and spinal trabecular bone loss in males, but no significant correlation with other clinical parameters. In one study of 84 patients ( 49 women and 35 men) with inflammatory bowel disease (IBD), clinical, dietary, radiologic, densitometric and biochemical assessments of BMD were performed. Seventeen patients had active CD and 19 had active UC. Thirty-two patients had never undergone corticosteroid therapy, but among those who had, cumulative lifetime corticosteroid dose was $10.5 \pm 13.0 \mathrm{~g}$ (range 0.3 to 64.8). In 29 patients (34\%), 12 of whom had never undergone corticosteroid therapy, serum osteocalcin was below $2 \mathrm{mg} / \mathrm{mL}$. The investigators concluded that no difference existed between patients who were undergoing corticosteroid treatment and patients who were not. However, bone density analysis (lumbar T score) by multiple regression analysis re- vealed that a statistically significant correlation among cumulative corticosteroid dose, sedimentation rate, age and osteocalcin level became apparent (1).

High doses and prolonged therapy appear to be associated with the greatest amount of bone damage in patients with other diseases. Researchers have reported a vertebral fracture prevalence of $34 \%$ in asthmatics treated with a mean dose of $12 \mathrm{mg} /$ day prednisone for a mean period of nine years (16). Similar fracture incidences have been reported for patients receiving long term corticosteroid therapy for rheumatoid arthritis. In 1991 Michel et al (17) reported that, over a five-year period, $34 \%$ of women receiving more than $5 \mathrm{mg} /$ day prednisone experienced a fracture. It thus seems prudent to maintain $\mathrm{CD}$ patients on the minimum dose of corticosteroid required to control symptoms.

Malnutrition: Patients with CD often must battle persistent malnutrition and the resultant weight loss. Malnutrition in IBD is caused by a multitude of factors: reduced oral intake, malabsorption, drugs, increased nutrient loss associated with diarrhea and increased requirements of chronic IBD. Individuals with $\mathrm{CD}$ often experience deficiencies in a number of key nutrients, including vitamin $B_{12}$, magnesium, zinc and copper. Many studies in the past 10 years have examined calcium and vitamin D malabsorption and their effect on BMD. Studies addressing the effect of fat malabsorption, enhanced absorption of dietary oxalate, hyperoxaluria secondary to steatorrhea and protein-losing enteropathy on osteoporotic bone have not yet been performed. It is impossible to quantify the role malnutrition plays in the osteoporosis of CD. Further study is required to delineate the importance of so many nutritional defects on skeletal demineralization.

\section{THERAPY}

Research into the treatment of CD-related osteoporosis has long been neglected. Few studies have involved IBD patients; most have concentrated on those with low BMD caused by hormonal change, chronic inflammation or long term glucocorticoid therapy.

Calcium and vitamin D: Calcium and vitamin D are generally used in the treatment of postmenopausal women and considered standard of care in osteoporosis patients. Because the average daily intake of calcium often falls below the daily recommended amount of 1.0 to $1.5 \mathrm{~g}$ in peri- and postmenopausal women, calcium supplements are often prescribed for these groups and give positive long term results. Supplements reduce menopausal bone loss and may increase bone mass in premenopausal women (18). Proponents suggest that calcium supplementation reduces parathyroid hormone secretion and, hence, bone turnover. Recently calcium replacement therapy (oral calcium carbonate $500 \mathrm{mg}$ bid) for induced osteoporosis was studied. Treatment with calcitriol and calcium supplements prevented bone loss in the spine, but not in the radius or femoral neck (19). However, Sambrook et al (20) concluded that calcium supplementation for steroid-using IBD patients with decreased bone density significantly increased bone density after one year. Therefore, while it is likely that calcium supplementation provides 
some benefit to patients, it cannot completely block steroidinduced bone loss (21).

The benefits of combining calcium and vitamin D supplementation for Crohn's patients are still unclear. CD patients have not yet been adequately studied. Compton and Creamer (6) found that vitamin D deficiency was common in CD patients despite adequate exposure to ultraviolet irradiation. As well, it has been clearly demonstrated that seasonal variations exist in vitamin D exposure (4). Some researchers recommend that any detectable vitamin D deficiency should be corrected with oral or parenteral administration of vitamin $\mathrm{D}$ at $400 \mathrm{IU} /$ day.

Other researchers do not believe that malabsorption of vitamin D plays a major role in the etiology of Crohn's-related osteoporosis. Bernstein et al (22) point out that patients with colonic disease have bone densities similar to those of patients with small bowel involvement. They suggest that, although calcium or vitamin D deficiency may exist despite normal biochemistry, bone histology is required to exclude this possibility definitively. As the controversy regarding the role of vitamin $\mathrm{D}$ and calcium supplementation in $\mathrm{CD}$ continues, the current trend in care favours supplementation.

Fluoride: Fluoride use has met with limited success in treating CD-related osteoporosis. Fluoride has a potent anabolic effect on bone and results in large, sustained increases in the density of trabecular bone (23). Fluoride $20 \mathrm{mg} /$ day also reduces fracture incidence in women with postmenopausal osteoporosis (24). However, Riggs and colleagues (23) found that osteomalacia resulted when higher doses of fluoride were used, and that the fracture rate was not reduced. Fluoride efficacy in preventing fractures due to steroid osteoporosis has not been unequivocally demonstrated. Furthermore, the dangers that high cumulative fluoride doses pose to bone quality must be considered. No studies have examined the use of fluoride by CD patients to prevent skeletal bone demineralization.

Calcitonin: Calcitonin is a hormone that directly inhibits osteoclast activity, thus reducing bone resorption. It is used in many countries for the routine treatment of postmenopausal osteoporosis. Studies done in the late 1980s and early 1990s showed that calcitonin was an effective prophylaxis against steroid osteoporosis in the short term. For example, Ringe and Welzel (25) found an increase in forearm bone mineral content of approximately $3 \%$ in steroid-dependent patients treated with parenteral calcitonin over six months; patients receiving placebo suffered a 3\% loss in BMD. Despite other promising short term studies, the side effects, cost and lack of intranasal preparations in some locations prohibit calcitonin's widespread use. As well, calcitonin's efficacy against the osteoporosis of CD has not been proven. Thus, its role seems limited to short term prevention of the steroidinduced osteoporosis that often accompanies IBD.

Hormone replacement therapy: Benefits of hormone replacement therapy to the premenopausal osteoporotic patient have been well proven. Sex hormone replacement removes at least one of the causes of rapid bone loss in women of this age. However, studies using hormone replacement for hypogonadal men have been slow to document the efficacy of this treatment. Hypogonadism is a frequent side effect of steroid treatment in men, and hypogonadism in other contexts is known to accelerate bone loss. Therefore some investigators (11) suggest providing testosterone replacement for these individuals. Grecu et al (26) reported that medroxyprogesterone acetate increased bone density in men with steroid osteoporosis. Their explanation was that progestogens compete for occupancy of the glucocorticoid receptor; thus, such competition was likely to take place in both bone and tissues. The question of routine testosterone replacement in hypogonad males and the efficacy of hormone replacement therapy in premenopausal women with CD has not been validated in large clinical trials.

Bisphosphonates - Pharmacology: The most promising treatment for osteoporosis seems to be bisphosphonates. This class of drugs is characterized by the presence of a P-C-P bond which gives them a high affinity for bone mineral. The biological activity of each bisphosphonate depends on the specific chemical structure of the side groups bound to the carbon atom of the P-C-P moiety. Bisphosphonates are potent inhibitors of osteoclast-mediated bone resorption, although their mode of action is not completely understood. There is some evidence that these compounds inhibit the activity of mature osteoclasts, and the proliferation, differentiation and access to bone of their precursors (27). Both the first and second generation bisphosphonates, etidronate, clodranate, and pamidronate, have been used successfully to treat established osteoporosis. Third generation bisphosphonates, eg, alendronate, are undergoing clinical trials involving osteoporosis patients.

Bisphosphonates and steroid-induced osteoporosis: Rigorous clinical trials have shown the effectiveness of bisphosphonates to treat steroid-induced osteoporosis. Results from a one-year, randomized, placebo controlled trial of pamidronate $150 \mathrm{mg} /$ day indicated that a $19 \%$ increase in vertebral mineral density, measured by quantitative CT, occurred in the treated group. There was a 19\% decline in those receiving placebo (28). One-third of these initial patients were followed for a second year. The gains in vertebral mineral density were maintained in the second year, whereas the placebo group showed a progressive decline in BMD (29).

Gallacher and co-workers (30) reported a 3.4\% mean increase in lumbar density in patients treated with $30 \mathrm{mg}$ pamidronate once every three months for a year. All patients participating in this study had corticosteroid-dependent lung disease, with an average prednisone use of $14 \mathrm{mg}$ (range 7.5 to 40 ) for an average of 14 years (range three to 30 ). The increase in bone density was similar to that noted for postmenopausal women who had received intermittent oral cyclical etidronate alternating with calcium for one year. These substances have a beneficial effect on spine and femoral bone density. Clodronate, given intermittently for one year, has been reported to increase vertebral BMD by $6 \%$. In at least three studies, the incidence of new vertebral fractures was reduced by more than $50 \%$. 
Bisphosphonates and IBD: Experience with bisphosphonates in patients with gut-related disease is limited. Passeri and associates (27) postulated that bisphosphonates given intermittently and/or at low dosages might reduce bone resorption to a greater degree than formation, inducing a persistent uncoupling and thus producing a constant positive effect on bone mass. However, their investigation involved the use of bisphosphonates in postmenopausal women. No study has been undertaken to examine the use of bisphosphonates in IBD patients. Therefore, the hypothesis of Passeri et al has yet to be proven.

\section{REFERENCES}

1. Abitol V, Roux C, Chaussade S, et al. Metabolic bone assessment in patients with inflammatory bowel disease. Gastroenterology 1995:108:417-22.

2. Bjarnason I, Li F. Mechanisms of osteoporosis in patients with inflammatory bowel disease. Gastroenterology 1994;106:652. (Abst)

3. Abitol V, Roux C, Chaussade S, Amor B, Couturier D. Longitudinal study of cortical and trabecular bone loss in patients with IBD. Gastroenterology 1994;106:642. (Abst)

4. Compston JE. Osteoporosis, corticosteroids and inflammatory bowel disease. Aliment Pharmacol Ther 1995;9:237-50.

5. Genant HK, Mall JC, Wagonfeld JB, Horst JV, Lanzl LV. Skeletal demineralization and growth retardation in inflammatory bowel disease. Invest Radiol 1976;11:541-9.

6. Compston JE, Creamer B. Plasma levels and intestinal absorption of 25-hydroxyvitamin D in patients with small bowel resection. Gut 1977;18:171-5.

7. Hessov I, Mosekilde L, Melsen F, et al. Osteopenia with normal vitamin D metabolises after small bowel resection for Crohn's disease. Scand J Gastroenterol 1984;19:691-6.

8. Croucher PI, Vedi S, Motley RF, Garrahan NJ, Stanton MR, Compston JE. Reduced bone formation in patients with osteoporosis associated with inflammatory bowel disease. Osteoporosis Int 1993;3:236-41.

9. Ghosh S, Cowen S, Hannan WJ, Ferguson A. Low bone mineral density in Crohn's disease, but not in ulcerative colitis, at diagnosis. Gastroenterology 1994:107:1031-9.

10. Giacomin D, Fries W. Bone alterations in Crohn's disease - a comparison between active and quiescent disease. Gastroenterology 1994;106:686. (Abst)

11. Reid IR, Grey AB. Corticosteroid osteoporosis. Bailleres Clin Rheumatol 1993;3:573-87.

12. Bressot C, Meunier PJ, Chapuy MC, et al. Histomorphometric profile, pathophysiology and reversibility of corticosteroid-induced osteoporosis. Metab Bone Dis Relat Res 1979;1:303-11.

13. Lo Cascio V, Bonucci E, Imbimbo B, et al. Bone loss in response to longterm glucocorticoid therapy. Bone Miner 1990;8:428-36.

14. Reid IR, Heap SW. Determinants of vertebral mineral density in patients receiving chronic glucocorticoid therapy. Arch Intern Med 1990;150:2545-8.

15. Motley RJ, Clements D, Evans WD, et al. A four-year longitudinal study of bone loss in patients with inflammatory bowel disease. Bone Miner 1993;23:95-104.

\section{TRENDS FOR THE FUTURE}

Further investigation of the effects of bisphosphonates on IBD patients is necessary. How will altered intestinal absorption affect an already poor oral bioavailability? Will the effects of long term steroid use, intermittent flares and general cachexia of malnutrition further nullify any beneficial effect of the bisphosphonate on BMD? How long can any potential improvement in BMD be sustained? Finally, will a sustained effect on bone resorption bring about an excessive inhibition of bone turnover, with a resultant negative effect on bone quality? These are only a few of the questions that need to be examined to characterize the effects of these preparations on CD-related osteoporosis.

16. Luengo M, Picado C, Del Rio L, Guanabens N, Montserrat JM, Setoain J. Treatment of steroid-induced osteopenia with calcitonin in corticosteroid-dependent asthma. Am Rev Respir Dis 1990;142:104-7.

17. Michel BA, Bloch DA, Fries JF. Predictors of fractures in early rheumatoid arthritis. J Rheumatol 1991;18:804-8.

18. Cumming RJ. Calcium intake and bone mass: A quantitative review of the evidence. Calcif Tissue Int 1990;47:194-201.

19. Lukert BP, Johnson BE, Robinson RG. Estrogen and progesterone replacement therapy reduces glucocorticoid-induced bone loss. J Bone Miner Res 1992;7:1063-9.

20. Sambrook PN, Birmingham J, Kelly S, et al. Prevention of corticosteroid osteoporosis: A comparison of calcium, calcitriol and calcitonin. J Bone Miner Res 1992;7(Suppl 1):96.

21. Harries AD, Brown R, Heatlet RV, Williams LA, Woodhead S, Rhodes S. Vitamin D status in Crohn's disease: Association with nutrition and disease activity. Gut 1985;26:1197-203.

22. Bernstein CN, Seeger LL, Anton PA, et al. Oral calcium and vitamin $\mathrm{D}$ does not impact on decreased bone density in inflammatory bowel disease: A prospective randomized placebo controlled study. Gastroenterology 1995;108:782. (Abst)

23. Riggs BL, Hodgson SF, O'Fallon WM, et al. Effect of fluoride treatment on the fracture rate in postmenopausal women with osteoporosis. N Engl J Med 1990;322:802-9.

24. Mamelle N, Meunier PJ, Dusan R, et al. Risk-benefit ration of sodium fluoride treatment in primary vertebral osteoporosis. Lancet 1988;ii:361-3.

25. Ringe JD, Welzel D. Salmon calcitonin in the therapy of corticoidinduced osteoporosis. Eur J Clin Pharmacol 1987;33:35-9.

26. Grecu EO, Weinshelbaum A, Simmons R. Effective therapy of glucocorticoid-induced osteoporosis with medroxyprogesterone acetate. Calcif Tissue Int 1990;46:294-9.

27. Passeri M, Baroni MC, Pedrazzoni M, et al. Intermittent treatment with intravenous 4-amino-1-hydroxybutylidene-1, 1-bisphosphonate (AHBuBP) in the therapy of postmenopausal osteoporosis. Bone Miner 1991;15:237-48.

28. Reid IR, King AR, Alexander CJ, Ibbertson HK. Prevention of steroid-induced osteoporosis with (3-amino-1-hydroxypropylidene)-1, 1-bisphosphonate (APD). Lancet 1988;i:143-6.

29. Reid IR, Heap SW, King AR, Ibbertson HK. Two-year follow-up of bisphosphonate (APD) treatment in steroid osteoporosis. Lancet 1988;ii:11444. (Lett)

30. Gallacher SJ, Fenner JAK, Anderson K. Intravenous pamidronate in the treatment of osteoporosis associated with corticosteroid dependent lung disease: An open pilot study. Thorax 1992;47:932-6. 


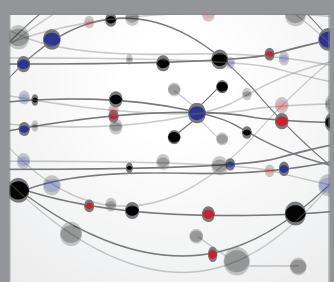

The Scientific World Journal
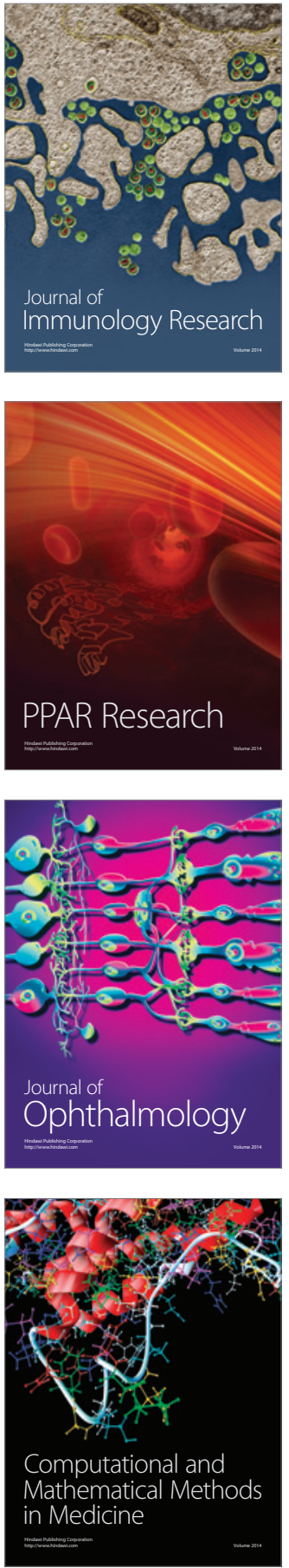

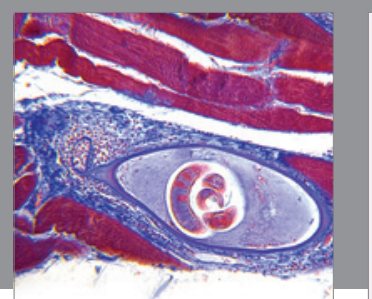

Gastroenterology Research and Practice

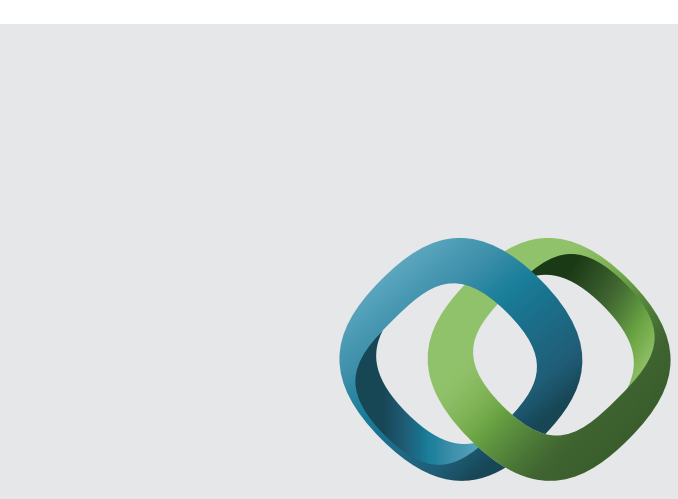

\section{Hindawi}

Submit your manuscripts at

http://www.hindawi.com
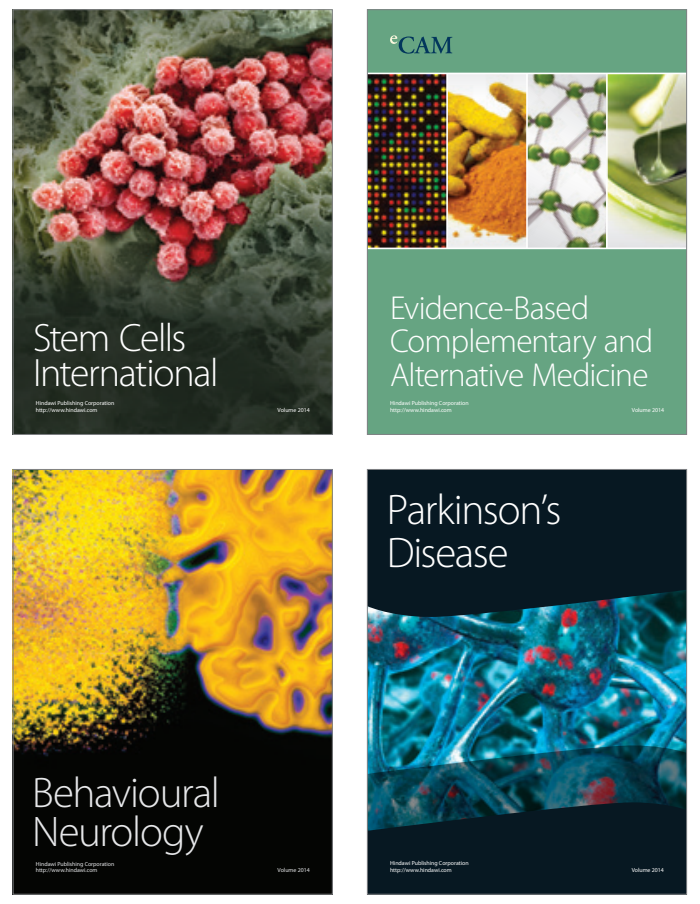
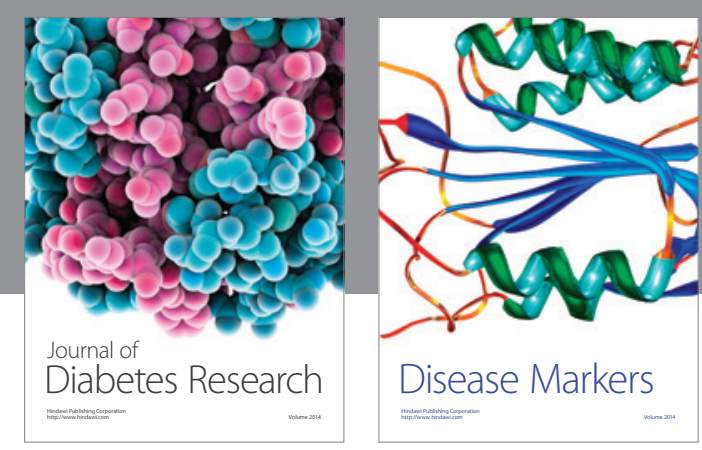

Disease Markers
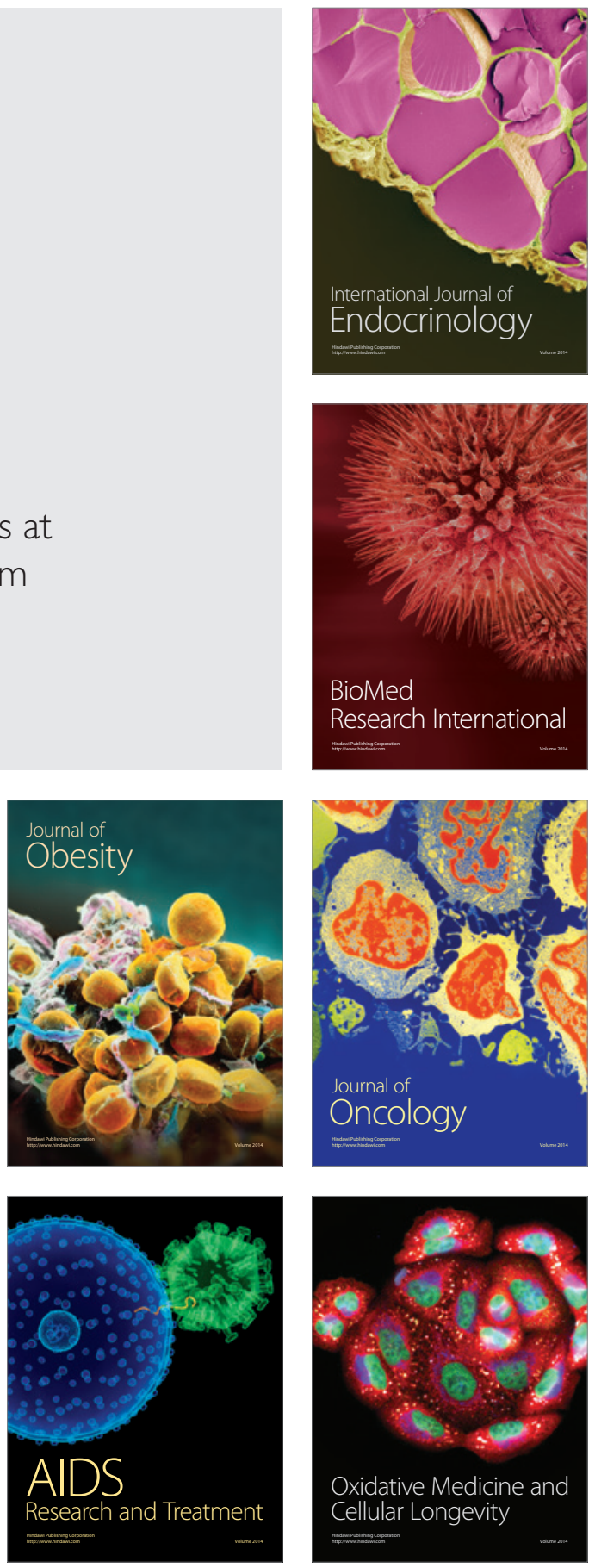